\title{
ASSOCIATION BETWEEN NUCLEATED RBC COUNT AND FOETAL ASPHYXIA AND ITS IMMEDIATE NEUROLOGICAL OUTCOME IN TERM NEWBORNS IN RIMS HOSPITAL
}

\author{
Bengia Abo', Namganglung Golmei ${ }^{2}$, Ch. Shyamsunder Singh ${ }^{3}$, Ch. Mangi Singh ${ }^{4}$, Kaushik Debnath ${ }^{5}$, Soram Goutam ${ }^{6}$ \\ 1 Junior Resident, Department of Paediatrics, Regional Institute of Medical Sciences, Imphal. \\ ${ }^{2}$ Assistant Professor, Department of Paediatrics, Regional Institute of Medical Sciences, Imphal. \\ ${ }^{3}$ Associate Professor, Department of Paediatrics, Regional Institute of Medical Sciences, Imphal. \\ 4 Professor, Department of Paediatrics, Regional Institute of Medical Sciences, Imphal. \\ 5 Professor, Department of Pathology, Regional Institute of Medical Sciences, Imphal. \\ ${ }^{6}$ Epidemiologist, Manipur Health Services.
}

\begin{abstract}
BACKGROUND

Perinatal asphyxia is an insult to the foetus or newborn due to lack of oxygen (hypoxia) and/or lack of perfusion (ischaemia) to various organs, of sufficient magnitude and duration to produce more than fleeting functional and/or biochemical changes. There are various studies available to indicate foetal asphyxia like intrapartum electronic foetal monitoring, foetal or umbilical cord $\mathrm{pH}$ measurement, Meconium-Stained Amniotic Fluid (MSAF), APGAR score, Hypoxic-Ischaemic Encephalopathy (HIE) and evidence of multiorgan dysfunction. But in a resource-limited institute a need for simpler and cheaper alternatives are sought. In this prospective analysis, we report our experience with a study on nucleated RBC (nRBC) count and its association with foetal asphyxia and its immediate neurological outcome in term newborns in RIMS Hospital, Imphal, Manipur.

The objective is to study the association between the nucleated RBC count and foetal asphyxia and its immediate neurological outcome in term newborns.
\end{abstract}

\section{MATERIALS AND METHODS}

In this case-control study conducted over 2 years in a tertiary care referral hospital in Manipur, India, 50 asphyxiated (study group) and 50 non-asphyxiated (control group) neonatal cord blood samples were randomly selected and analysed.

\section{RESULTS}

nRBC counts were significantly higher in those with meconium-stained amniotic fluid (MSAF) (12.66 \pm 6.17$)$ than in normal amniotic fluid group (9.25 \pm 5.88$)$. nRBC/100 WBCs were also significantly elevated in asphyxiated newborns (14.10 \pm 4.79 ) in comparison to non-asphyxiated group ( $5.44 \pm 3.47$ ). As the stage of Hypoxic-Ischaemic Encephalopathy (HIE) increased from grade I (9.4 \pm 4.57 ) to grade III $(21 \pm 2.94)$, nRBC count also increased in frequency showing a direct proportion.

\section{CONCLUSION}

In limited health care settings, $\mathrm{nRBC}$ count can be an easy and economical alternative for detecting perinatal asphyxia and also the severity of HIE.

\section{KEYWORDS}

Newborns, Perinatal Asphyxia, Nucleated RBC, HIE, MSAF.

HOW TO CITE THIS ARTICLE: Abo B, Golmei N, Singh CS, et al. Association between nucleated RBC count and foetal asphyxia and its immediate neurological outcome in term newborns in RIMS hospital. J. Evolution Med. Dent. Sci. 2017;6(95):6931-6934, DOI: $10.14260 /$ jemds/2017/1504

\section{BACKGROUND}

Perinatal asphyxia is a common and serious neonatal problem worldwide and contributes considerably to both neonatal morbidity and mortality. According to the World Health Organization (WHO) in 2000, of the 130 million infants born globally each year, approximately 4 million babies die before they reach the age of 1 month. ${ }^{1}$ Furthermore, of 1.2 million neonatal deaths in India, 300,000-350,000 babies die due to perinatal asphyxia mostly within first 3 days of life. ${ }^{2}$

'Financial or Other Competing Interest': None.

Submission 18-08-2017, Peer Review 06-12-2017,

Acceptance 14-12-2017, Published 23-12-2017.

Corresponding Author:

Dr. Namganglung Golmei,

Department of Paediatrics,

Regional Institute of Medical Sciences,

Imphal.

E-mail: namganglung@gmail.com

DOI: $10.14260 /$ jemds $/ 2017 / 1504$

\section{(c) (i) ()}

The common complications of asphyxia may be acute like irreversible renal cortical necrosis, persistent pulmonary hypertension of the newborn, hypotension, cardiogenic shock or heart failure and chronic conditions such as epilepsies or cerebral palsy. ${ }^{3-5}$ Secondary to birth asphyxia, a postnatal manifestation of hypoxic-ischaemic encephalopathy (HIE) is frequently observed to be associated with either mild or severe organ damage in asphyxiated newborns, both leading to the development of chronic neurodevelopmental sequelae. ${ }^{6}$

Many parameters are used to predict perinatal asphyxia, namely - intrapartum electronic foetal monitoring, foetal or umbilical cord pH measurement, meconium-stained amniotic fluid (MSAF), APGAR score, hypoxic-ischaemic encephalopathy (HIE) and evidence of multiorgan dysfunction. ${ }^{7}$ Umbilical cord blood gas analysis is now recommended in all high-risk deliveries by both the British and American College of Obstetricians and Gynaecologists. An umbilical cord $\mathrm{pH}<7.2$ immediately after birth is used as a prognostic factor for unfavourable short-term outcome in newborn. ${ }^{8}$ But blood gas analysers are not always available in 
many of the health care centres especially in less developed areas. Recent studies have focused on the utility of nucleated red blood cell count (nRBC), which may be readily examined with minimal means as a marker of perinatal asphyxia.9,10,11

Nucleated red blood cells (nRBCs) are immature erythrocytes commonly found in the peripheral blood of newborns with counts varying widely at birth. ${ }^{12}$ Among the many causes for increased nRBC count, foetal hypoxia has been postulated to stimulate an upsurge in numbers of circulating nRBCs and the increased numbers of nRBCs may indicate the severity and duration of hypoxia. Distinct nRBC patterns may also be related to the timing of foetal injury, implying that $\mathrm{nRBC}$ count may be helpful in determining the timing of foetal neurological impairment. ${ }^{13}$

In less developed countries like ours, perinatal asphyxia remains a major cause of morbidity and mortality presenting a formidable range of problems. The pattern of risk factors, the nature of sequelae and the options as well as priorities for intervention (both preventive and therapeutic) are significantly different than in the developed countries. As examination of $\mathrm{nRBC}$ count is easily available, this study was designed to determine the utilities of nRBC count as a detector of foetal asphyxia in term newborns along with the short-term outcome in a resource-limited health care centre.

\section{Objectives}

To study the association between the nucleated RBC count and foetal asphyxia and its immediate neurological outcome in term newborns.

\section{MATERIALS AND METHODS}

Study Setting and Duration: This hospital-based case-control study was conducted in the Department of Paediatrics, in collaboration with the Departments of Pathology, Regional Institute of Medical Sciences, Imphal during the period from August 2008 to July 2010 with due clearance by the institutional ethical committee.

Sample Size and Sampling: Sample size was calculated using the following formula and parameters for comparing 2 independent proportions as follows:

Subjects per group $(n)=P_{1}\left(1-P_{1}\right)+P_{2}\left(1-P_{2}\right) /\left(P_{2}-P_{1}\right)^{2} x f(\alpha, \beta)$ Where,

$\mathrm{P}_{1}=0.26$ (proportion of cases with nucleated RBCs) ${ }^{23}$

$\mathrm{P}_{2}=0.06$ (proportion of controls with nucleated $\mathrm{RBCs}$ ) $^{23}$

$f(\alpha, \beta)=7.85$ for $80 \%$ power

From above, $\mathrm{n}=0.26(1-0.26)+0.06(1-0.06) /(0.06-0.26)^{2} \mathrm{x}$ 7.85

So, based on these parameters, the calculated sample size was 48.827 and it was rounded to 50 (fifty) for our convenience.

\section{Cases}

Newborns with Apgar scores $\leq 5$ at 5 minutes (perinatal asphyxia)..$^{14}$

\section{Controls}

Newborns with Apgar score $\geq 8$ at 1 minute (without perinatal asphyxia). ${ }^{14}$

\section{Recruitment of Study Subjects}

Fifty neonates with perinatal asphyxia (Apgar score $\leq 5$ at 5 minutes) delivered in Labour Room, Obstetrics and Gynaecology Department; RIMS were randomly selected and included in the case group. Fifty neonates without history of perinatal asphyxia (Apgar score $\geq 8$ at 1 minute) were randomly selected and included in the control group.

\section{Inclusion Criteria}

1. Newborns with evidence of foetal distress - decreased foetal movements, tachycardia or bradycardia.

2. Neonates having history of meconium-stained amniotic fluid (MSAF).

3. Term babies with birth weight $\geq 2.5 \mathrm{~kg}$.

4. 5 minutes Apgar score of $\leq 5$.

\section{Exclusion Criteria}

1. Babies with gross congenital anomalies.

2. Chromosomal anomalies.

3. Rh incompatibility.

4. Septicaemia.

5. Parents refusing consent.

\section{Methodology}

In this study, the maternal and birth history along with clinical findings were recorded from the enrolled babies after stabilisation and thorough examination in a predesigned proforma. Cord blood samples ( $2 \mathrm{~mL}$ ) were collected in EDTA (ethylene diamine tetra-acetate) vials immediately after delivery and dispatched to the Pathology (Haematology) laboratory for analysis. Peripheral smear examination was carried out with special reference to nRBC count in both the groups. Routine staining of blood film was done using Leishman's stain. Apgar score was used for evaluation of the enrolled subjects. Newborns with Apgar scores $\leq 5$ at 5 minutes was considered asphyxiated and those with $\geq 8$ at 1 minute was considered normal. ${ }^{14}$

Grading of neonates with asphyxia was done according to Sarnat and Sarnat staging. ${ }^{15}$ The clinical spectrum of HIE was described as mild, moderate and severe. Infants can progress from mild to moderate and/or severe encephalopathy over 72 hours following the hypoxic-ischaemic insult. The various stages were correlated with nucleated red blood cell count per 100 white blood cell count. 15

After initiated resuscitation and stabilisation, the asphyxiated neonate was transferred to the Neonatal Intensive Care Unit (NICU) for further observation and management. The control group was kept in the Post-Natal ward.

The data were recorded in a pre-designed proforma, and analysed using SPSS version 19. The results are expressed in descriptive statistics, the association was assessed using oddratio (OR) and Chi-square test $\left(\chi^{2}\right)$; and $p$-value of $<0.05$ was considered statistically significant.

\section{RESULTS}

A total of 100 subjects - 50 asphyxiated (case group) and 50 non-asphyxiated (control group) were randomly selected from among the delivered babies. There were 27 males (54\%) and $23(46 \%)$ females (M: $\mathrm{F}=1.17: 1)$ in the case group, whereas male: female ratio in the control group was 1.27:1. The average weight of the case babies was $3.17 \pm 0.33 \mathrm{~kg}$ (3.04 
$\pm 0.30 \mathrm{~kg}$ for the control group). 42 babies (84\%) were born by vaginal delivery; the remaining $8(16 \%)$ were delivered through emergency lower caesarean section or assisted venous procedures.

In the case group, $15(30 \%)$ babies were born with meconium-stained amniotic fluid; the remaining 35 (70\%) babies did not have meconium staining of amniotic fluid. All the babies in the control group were born without meconium staining.

When the nRBC count was compared between the two groups, the nRBC count significantly higher in babies born through MSAF $(12.66 \pm 6.17)$ than in normal amniotic fluid (9.25 \pm 5.88$)$. [Table -1$]$.

$5(10 \%)$ of the case group had a 1 minute Apgar score of 2 ; 23 (46\%), 18 (36\%) and 4 (8\%) babies had scores of 3, 4 and 5 respectively. The number of babies having Apgar scores of 2 , 3,4 and 5 at 5 minutes were 1 (2\%), 8 (16\%), 17 (34\%) and 24 (48\%) respectively.

The mean \pm SD of nucleated red blood cells in the study group at a five minutes Apgar score of 0-3 was found to be $17.66 \pm 5.74$ per $100 \mathrm{WBCs}$, compared to $13.31 \pm 4.25$ per 100 WBCs in neonates having Apgar scores of 4-5. [Table - 2].

Nucleated red blood cells/100 WBCs were significantly higher in number in asphyxiated newborns $(14.10 \pm 4.79)$ in comparison to non-asphyxiated group (Mean \pm SD $=5.44 \pm$ 3.47) ( $\mathrm{p}$ value $<0.05$ ) as shown in Table - 3 .

It was also observed that, as the stage of HIE increased from I to III the nucleated red blood cells increased in frequency showing a direct proportion. (Table - 4).

\begin{tabular}{|c|c|c|}
\hline Amniotic Fluid & N (\%) & Mean nRBC Count \pm SD \\
\hline MSAF & $15(30)$ & $12.66 \pm 6.17$ \\
\hline Clear AF & $35(70)$ & $9.25 \pm 5.88$ \\
\hline \multicolumn{3}{|c|}{ Table 1. Association of nRBC \& Types of Amniotic Fluid } \\
(AF)
\end{tabular}

\begin{tabular}{|c|c|}
\hline Apgar Score & nRBCs (Mean \pm SD) \\
\hline $0-3$ & $17.66 \pm 5.74$ \\
\hline $4-5$ & $13.31 \pm 4.25$ \\
\hline \multicolumn{2}{|c|}{ Table 2. Association of Apgar Score \& $\boldsymbol{n R B C s}$} \\
\hline
\end{tabular}

\begin{tabular}{|c|c|c|c|c|c|c|c|}
\hline  & 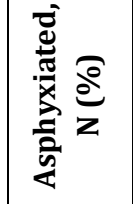 & 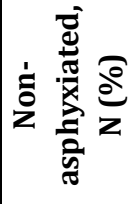 & $\underbrace{z}_{0}$ & 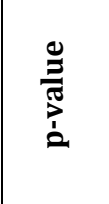 & ชี & $\underset{x}{x}$ & t \\
\hline$>10$ & $38(76)$ & $5(10)$ & $43(43)$ & \multirow{3}{*}{$<0.005$} & \multirow{3}{*}{28.72} & \multirow{3}{*}{44.43} & \multirow{3}{*}{$\begin{array}{lll}3 & 1\end{array}$} \\
\hline$\leq 10$ & $12(24)$ & $45(90)$ & 57 (57) & & & & \\
\hline \begin{tabular}{|l|} 
Total \\
\end{tabular} & $50(100)$ & $50(100)$ & $100(100)$ & & & & \\
\hline
\end{tabular}

\begin{tabular}{|c|c|c|}
\hline Stage of HIE & $\begin{array}{c}\text { Range of } \\
\text { nRBCs/100 WBCs }\end{array}$ & Mean \pm SD \\
\hline I & $2-18$ & $9.4 \pm 4.57$ \\
\hline II & $7-21$ & $14.45 \pm 4.25$ \\
\hline III & $18-24$ & $21 \pm 2.94$ \\
\hline Table 4. Association of Stages of HIE and Range of \\
Nucleated RBCs/100 WBCs \\
\hline
\end{tabular}

\section{DISCUSSION}

In the present study, 15 newborns (30\%) of the asphyxiated group were born to mothers with history of meconium-stained amniotic fluid. The mean $\mathrm{nRBC}$ count \pm SD in the babies born to meconium-stained amniotic fluid was found to be higher $(12.66 \pm 6.17)$ than that of babies born to clear amniotic fluid (9.25 \pm 5.88$)$. A similar finding was reported by Papa D et al ${ }^{11}$ in their study wherein they correlated $n R B C$ count with MSAF and found the mean $\mathrm{nRBC}$ count \pm SD among MSAF was 27.41 \pm 10.13 and among non-MSAF was $13.53 \pm 6.37$. Darkhaneh RF et $\mathrm{al}^{16}$ also reported a mean $\mathrm{nRBC}$ count of $8.67 \pm 6.54$ in neonates born in presence of MSAF compared to $3.88 \pm 3.92$ in non-asphyxiated neonates without history of meconium staining, indicative of a mean nRBC difference of 4.79 units between the study and control group with a significantly higher $n R B C$ count in the study group $(p=0.001)$. The presence of meconium in the amniotic fluid has long been thought to indicate foetal stress. This study showed that, as hypothesised, infants with meconium-stained amniotic fluid had higher absolute nRBC counts than infants with clear amniotic fluid. The finding supports the view that neonates with meconiumstained amniotic fluid suffer from foetal hypoxia since raised nRBC levels are related to intrauterine hypoxia. Tissue hypoxia results in increased levels of erythropoietin, which in turn leads to stimulation of erythropoiesis, thus increasing the number of circulating nRBCs. ${ }^{17}$

In this study, when Apgar score was analysed in relation to the nucleated red blood cells, the mean \pm SD nRBC value at a 5 minute Apgar score of $0-3$ was $17.66 \pm 5.74$ per $100 \mathrm{WBCs}$. The count decreased to a value of $13.31 \pm 4.25$ per $100 \mathrm{WBCs}$ at a score of 4-5 showing an inverse proportion. These findings are similar to the study findings of Behera JN et al ${ }^{18}$ who reported that the mean nRBC count of $104 \pm 26.22$ at an Apgar score of 0-3 decreased to $32 \pm 10.0$ at an Apgar score of 4-5. Papa D et al ${ }^{11}$ also reported similar findings with nRBCs (mean \pm SD) of $26.23 \pm 10.01$ and $13.04 \pm 6.42$ in 5-minute Apgar scores of $>6$ and $<6$ respectively showing an inverse proportion.

Of the 50 neonates in the asphyxiated group, $21(42 \%)$ were in HIE stage I, 23 (46\%) in HIE stage II and 6 (12\%) in HIE stage III. As the stage of HIE progressed from I to III, the nucleated red blood cells increased in frequency from $9.4 \pm$ 4.57 in HIE-I, to $14.45 \pm 4.25$ in HIE-II, and to $21 \pm 2.94$ in HIE stage III. In a study by Elayoty $\mathrm{M}$ et al, ${ }^{19}$ asphyxiated neonates exhibited a significantly higher number of nRBC/100 white blood cells (median=120; range: 5- 835) than the control group (median=1; range: $0-8 ; p=0.001$ ). Newborns with severe neurologic impairment (group III) had significantly higher cord blood nRBC than group II and I ( $\mathrm{p}=0.001$ each).

Boskabadi $\mathrm{H}$ et $\mathrm{al}^{20}$ demonstrated nRBC counts of $3.87 / 100$ leucocytes for healthy infants, 9.75 for asphyxiated neonates without HIE, 11.94 for HIE grade I, 21.08 for grade II and 29.18 for HIE grade III. They found a significant relationship between $\mathrm{nRBC} / 100 \mathrm{WBC}$ and the degree of encephalopathy $(\mathrm{p}<0.001)$. Korst $\mathrm{LM}$ et $\mathrm{al}^{21}$ also found a higher level of nRBC in neurologically impaired neonates (30.3. \pm 77.5$)$ than in normal neonates $(3.4 \pm 3.0)$.

The mortality among cases of HIE was highest in stage III, accounting for an overall of $6 \%$ of deaths in the asphyxiated group and $50 \%$ of deaths in stage III of HIE. Out of 6 neonates in HIE stage III, 3 neonates died in the ward. There were no mortalities in stage I and II. Pfenninger et al, ${ }^{22}$ reported a 51\% 
overall mortality rate from among 27 neonates with hypoxicischaemic encephalopathy. In a similar study Papa D et al, ${ }^{4} 11$ found an overall mortality rate of $34 \%$. Behera JN et al ${ }^{18}$ reported a mortality of $9 \%$ in HIE stage II, $68.1 \%$ in stage III, and an overall mortality of $34 \%$ in their study. Among 36 infants, Boskabadi et al 20 found favourable outcome (normal neurologic development) in 22 infants and with adverse outcome (10 deaths within the first month of life and 6 with neurodevelopmental sequelae) in the other 16 infants.

The diagnostic validity of nucleated red blood cells in this study showed a sensitivity of $76 \%$, specificity of $90 \%$, positive predictive value of $88.3 \%$ and a negative predictive value of $78.9 \%$. Boskabadi $\mathrm{H}$ et $\mathrm{al}^{20}$ reported that for an nRBC count of $>70 / \mathrm{mm}^{3}$, the sensitivity and specificity for the diagnosis of foetal asphyxia were $83.4 \%$ and $73.5 \%$ respectively. Behera JN et al, 18 in their study reported a sensitivity of $94 \%$, specificity of $98 \%$, positive predictive value of $97.9 \%$, negative predictive value of $94.2 \%$ and an overall accuracy of $98 \%$.

\section{CONCLUSION}

In this study, a strong association is found to be present between nucleated RBCs and perinatal asphyxia, directly proportional with the degree of neurological outcome. So, in a resource-limited setup, nRBCs count may be used as an easy, economical and reliable alternative to detect perinatal asphyxia and predict the neurological outcome such as HIE in term newborns.

\section{REFERENCES}

[1] Lawn JE, Cousens S, Zupan J, et al. 4 million neonatal deaths: When? Where? Why? Lancet 2005;365(9462):891-900.

[2] World Health Organization. Neonatal and perinatal mortality 2004: Country, Regional and Global Estimates. Geneva: WHO, 2006.

[3] Klein JM, Zlatnik FJ, Hein HA. Multiorgan system failure from perinatal asphyxia. Iowa Perinat Lett 2005;26(1):1-4.

[4] Gupta BD, Sharma P, Bagla J, et al. Renal failure in asphyxiated neonates. Indian Pediatr 2005;42(9):92834.

[5] Sergeyeva RA, Ismagilov MF. Cerebral palsy. Etiology and pathogenesis. Neurol Bull 1998:1-2.

[6] Perlman JM. Brain injury in the term infant. Semin Perinatol 2004;28(6):415-24.

[7] World Health Organization. Birth asphyxia-summary of the previous meeting and protocol review. Geneva: WHO, 2007.

[8] Ahmadpour-Kacho M, Zahedpasha Y, Hagshenas M, et al. Short term outcome of neonates born with abnormal umbilical cord arterial blood gases. Iran J Pediatr 2015;25(3):e174.
[9] Phelan JP, Ahn MO, Korst LM, et al. Nucleated red blood cells: a marker for fetal asphyxia? Am J Obstet Gynecol 1995;173(5):1380-4.

[10] McCarthy JM, Capullari T, Thompson Z, et al. Umbilical cord nucleated red blood cell counts: normal values and the effect of labor. J Perinatol 2006;26(2):89-92.

[11] Papa D, Jyotsna GP, Ashok BB. Cord blood nucleated red blood cell count - a marker of fetal asphyxia. J Obstet Gynecol India 2008;58(1):45-8.

[12] Nicolaides KH, Thilaganathan B, Mibashan RS. Cordocentesis in the investigation of fetal erythropoiesis. Am J Obstet Gynecol 1989;161(5):1197-200.

[13] Buonocore G, Perrone S, Gioia D, et al. Nucleated red blood cell count at birth as an index of perinatal brain damage. Am J Obstet Gynecol 1999;181(6):1500-5.

[14] Ringer SA. Resuscitation in the delivery room. In: Cloherty JP, Eichenwald EC, Stark AR. eds. Manual of neonatal care. $6^{\text {th }}$ edn. Philadelphia: Lippincott Williams and Wilkins 2008:59-71.

[15] Sarnat HB, Sarnat MS. Neonatal encephalopathy following fetal distress. A clinical and electroencephalographic study. Arch Neurol 1976;33(10):696-705.

[16] Darkhaneh RF, Asgharnia M, Yousefi TZ. Comparison of Nucleated Red Blood Cell (NRBC) in term neonatal umbilical cord blood between neonate with Meconium Stained Amniotic Fluid (MSAF) and clear amniotic fluid. J Turkish- German Gynecol Assoc 2008;9(2):29-31.

[17] Hermansen MC. Nucleated red blood cells in the fetus and newborn. Arch Dis Child Fetal Neonatal Ed 2001;84(3):F211-5.

[18] Behera JN, Kuila M, Rath BK. Nucleated red blood cell count as a predictor of Foetal asphyxia and its immediate neurological outcome. Pedi-Info 2007;10(2):9-14.

[19] Elayoty M, Aref S, Abdelhady H. Study of nucleated red blood cells in evaluation of fetal asphyxia. Acta Clin Croat 2002;41:135-86.

[20] Boskabadi H, Maamouri G, Sadeghian MH, et al. Early diagnosis of perinatal asphyxia by nucleated red blood cell count: a case study. Archives of Iranian Medicine 2010;13(4):275-81.

[21] Korst LM, Phelan JP, Ahn MO, et al. Nucleated red blood cells: an update on the marker for fetal asphyxia. American Journal of Obstetrics and Gynaecology 1996;175(4 Pt 1):843-6.

[22] Pfenninger J, Bachmann D, Wagner BP. Survivors with bad outcome after hypoxic-ischaemic encephalopathy: full-term neonates compare unfavourably with children. Swiss Med Wkly 2001;131(19-20):267-72. 